\title{
Decomposition of educational differences in life expectancy by age and causes of death among South Korean adults
}

\author{
Kyunghee Jung-Choi ${ }^{1}$, Young-Ho Khang ${ }^{2}$, Hong-Jun $\mathrm{Cho}^{3}$ and Sung-Cheol Yun ${ }^{4^{*}}$
}

\begin{abstract}
Background: Decomposition of socioeconomic inequalities in life expectancy by ages and causes allow us to better understand the nature of socioeconomic mortality inequalities and to suggest priority areas for policy and intervention. This study aimed to quantify age- and cause-specific contributions to socioeconomic differences in life expectancy at age 25 by educational level among South Korean adult men and women.

Methods: We used National Death Registration records in 2005 (129,940 men and 106,188 women) and national census data in 2005 (15, 215, 523 men and 16,077,137 women aged 25 and over). Educational attainment as the indicator of socioeconomic position was categorized into elementary school graduation or less, middle or high school graduation, and college graduation or higher. Differences in life expectancy at age 25 by educational level were estimated by age- and cause-specific mortality differences using Arriaga's decomposition method.

Results: Differences in life expectancy at age 25 between college or higher education and elementary or less education were 16.23 years in men and 7.69 years in women. Young adult groups aged 35-49 in men and aged 25-39 in women contributed substantially to the differences between college or higher education and elementary or less education in life expectancy. Suicide and liver disease were the most important causes of death contributing to the differences in life expectancy in young adult groups. For older age groups, cerebrovascular disease and lung cancer were important to explain educational differential in life expectancy at 25-29 between college or higher education and middle or higher education.

Conclusions: The contribution of the causes of death to socioeconomic inequality in life expectancy at age 25 in South Korea varied by age groups and differed by educational comparisons. The age specific contributions for different causes of death to life expectancy inequalities by educational attainment should be taken into account in establishing effective policy strategies to reduce socioeconomic inequalities in life expectancy.
\end{abstract}

Keywords: Life expectancy, Socioeconomic inequality, Socioeconomic factors, Health status disparities, Contribution

\section{Background}

Investigation into contributions by specific causes and age groups to absolute socioeconomic inequalities in total mortality is important to understand mechanisms of socioeconomic health inequalities and to establish policies and intervention programs to reduce socioeconomic inequalities in health. Many studies have reported the contribution of causes of death in specific age groups

\footnotetext{
*Correspondence: ysch97@amc.seoul.kr

${ }^{4}$ Department of Clinical Epidemiology and Biostatistics, Asan Medical Center, University of Ulsan College of Medicine, 388-1 Pungnap2-dong, Songpa-gu, Seoul 138-736, Korea

Full list of author information is available at the end of the article
}

to socioeconomic mortality inequalities in Asia as well as in western countries [1-5]. They revealed that the pattern of the contribution by specific causes of death varied by countries, which informs of different policy priorities for different countries.

Life expectancy is the expected years of life of a person remaining at a given age and a summary measure for mortality determined by the probability of death at each age [6]. It has important strengths in that it can be more easily understood than the age-standardized mortality rates by the public and compared between countries or changes over time [7-9]. In addition, life expectancy can 
be decomposed by death causes and specific age groups, which allows us to better understand mechanisms of socioeconomic inequalities in mortality.

Decomposition of socioeconomic inequalities in life expectancy by ages or causes has been mainly performed in western countries [10-12]. Some studies showed agespecific contributions to socioeconomic inequalities in life expectancy over time $[7,10,13,14]$ while other studies reported patterns of cause-specific contributions [6,11-14]. However, there is still a paucity of studies investigating age and death cause contributions socioeconomic difference in life expectancy by socioeconomic position (SEP) with use of national data covering whole population. This study aimed to quantify age- and cause-specific contributions to socioeconomic differences in life expectancy at age 25 by educational level among adult men and women in South Korea (hereafter 'Korea') to provide evidence guiding intervention priorities.

\section{Methods}

\section{Study subjects}

We used national death certificate and census data in 2005 from Statistics Korea. The number of total deaths aged 25 and over was 239,166 in 2005. After excluding data without any information on level of education, causes of death or age being missing or inaccurate, the present study included 236,128 deaths (98.7\% of total deaths, 129,940 men and 106,188 women). In 2005 national census, 15, 215, 523 men and 16,077,137 women aged 25 and over were identified and included in this study.

By law, all deaths must be reported to Statistics Korea within a month of their occurrence in Korea. Death registration in Korea is known to be complete for deaths occurring among those aged 1+ years since the mid-1980s [15]. Death certification by a physician was suggested as a very important factor to improve accuracy in reporting causes of death in Korea [16,17]. The proportion of death certified by physicians was $86.9 \%$ in 2005 . The reliability of the educational level in death certificate data was reported to be substantial [18].

This study was approved by the Asan Medical Center Institutional Review Board, Seoul, Korea.

\section{Socioeconomic position (SEP) indicator}

A level of own education was used as the SEP indicator of this study. Educational attainment was categorized into elementary school graduation or less, middle or high school graduation, or college graduation or higher. Elementary school and high school in Korea correspond to the International Standard Classification of Education (ISCED) 1 and ISCED 3, respectively whereas there is no schooling system in Korea relevant to ISCED 4 [19]. College is classified as ISCED 5.
Educational achievement among Korean population during the past decades has been remarkable along with the huge economic development. The enrollment rate in elementary school was $69.8 \%$ in 1951 but reached to $97.7 \%$ in 1980 and $98.6 \%$ in 2012 [20]. An explosive increase was observed for the enrollment rate in college or higher education skyrocketing from $4.2 \%$ in 1965 to over $60 \%$ in 2005 . Thus, a very different educational distribution with age groups can be found in Korea. For example, $61.5 \%$ of women at age $25-29$ years are classified into college of higher graduation while $76.1 \%$ of women at age 60-64 years are classified into elementary school graduation or less in 2005 [21].

\section{Statistical analysis}

For life expectancy at age 25, life tables were constructed using 5- year probabilities of death by educational level. 5 -year probabilities of death were calculated based on the age-specific death rates which were estimated from the number of death in death certificate data and the number of population in census data by age and educational level. Differences in life expectancy at age 25 by educational level were calculated.

Age- and cause-specific contributions to the educational differences in life expectancy at age 25 were estimated using Arriaga's decomposition method [22]. The Arriaga method which has been widely used to decompose differences in life expectancy concerns a direct effect, an indirect effect, and an interaction effect of mortality difference on life expectancy. The direct effect reflects a consequence of a mortality difference in that age group. The indirect effect is due to a change in the number of survivors at the end of that age interval from a mortality change within a specific age group. The interaction effect results from the combination of the changed number of survivors at the end of the age interval and the lower (or higher) mortality rates at older ages. The total contribution of each age group to the change in life expectancy can be calculated by adding the direct, indirect and interaction effect $[22,23]$. By Arriaga's decomposition method, the difference in life expectancy can be decomposed into ages and causes of death which enable us to explain life expectancy differentials in terms of the contribution of each factor. Higher mortality rate in low SEP than high SEP makes a positive contribution to socioeconomic differences in life expectancy. In other words, a positive contribution refers a contribution to the increase in educational differentials in life expectancy. The total life expectancy differential by SEP is the sum of the number of years attributed negatively or positively by deaths in each age group or cause.

Life expectancy was calculated by causes of death. A total of 8 broad and 17 specific ( 15 for men and 14 for women) causes of death were selected based on the main causes of death in South Korea [24] (see Table 1). 
Table 1 Crude death rates $(/ 100,000)$ by main causes of death in 2005 among Korean men and women

\begin{tabular}{llll}
\hline & Total & Men & Women \\
\hline All causes & 504.3 & 554.7 & 453.5 \\
Infectious and parasitic diseases (A00-B99) & 11.4 & 14.1 & 8.8 \\
Respiratory tuberculosis (A15-A16) & 5.5 & 7.8 & 3.3 \\
All Cancers (C00-D48) & 136.0 & 171.0 & 100.9 \\
Stomach cancer (C16) & 22.6 & 29.4 & 15.7 \\
Liver cancer (C22) & 22.5 & 33.8 & 11.2 \\
Lung/bronchial cancer (C33-C34) & 28.4 & 41.6 & 15.0 \\
Endocrine, nutritional \& metabolic diseases & 25.5 & 25.8 & 25.3 \\
(E00-E88) & & & \\
Diabetes mellitus (E10-E14) & 24.2 & 24.4 & 24.0 \\
Disease of the circulatory system (I00-199) & 116.2 & 112.1 & 120.4 \\
Hypertensive disease (I10-113) & 9.3 & 6.6 & 12.1 \\
Heart disease (I20-I51) & 39.6 & 41.0 & 38.2 \\
Cerebrovascular disease (I60-169) & 64.3 & 61.2 & 67.3 \\
Diseases of the respiratory system (J00-J98) & 29.4 & 34.6 & 24.1 \\
Pneumonia (J12-J18) & 8.6 & 9.0 & 8.2 \\
Chronic lower respiratory disease (J40-J47) & 15.5 & 18.9 & 12.2 \\
Diseases of the digestive system (K00-K92) & 23.1 & 33.4 & 12.8 \\
Liver diseases (K70-K76) & 17.3 & 27.5 & 7.1 \\
All external causes (V01-Y89) & 63.6 & 86.2 & 40.8 \\
Transport accidents (V01-V99) & 16.3 & 24.0 & 8.6 \\
Suicide (X60-X84) & 26.1 & 34.9 & 17.3 \\
\hline & & &
\end{tabular}

Data source: Statistics Korea. The Causes of Death Statistics in 2005.

Causes of death were coded using the $10^{\text {th }}$ version of the International Classification of Disease (ICD-10).

\section{Results}

Table 2 shows numbers of subjects and deaths and life expectancy at age 25 according to educational level. Middle or high school graduates accounted for about half of total subjects among both men and women ( $50.3 \%$ for men and $52.1 \%$ for women) while the numbers of deaths were the greatest among those with elementary school graduation or less $(41.9 \%$ for men and $57.6 \%$ for women). Life expectancy at age 25 was 48.39 years in men and 54.75 years in women, respectively. Life expectancy stepwisely increased with education levels. Differences in life expectancy at age 25 between college or higher education and elementary or less education were 16.23 years in men and 7.69 years in women.

Figure 1 shows age-specific contributions to the educational gap in life expectancy among Korean men and women. In men, those aged $40-44$ as a single age group contributed most (13.9\%) to educational differences in life expectancy at age 25 between college or higher education and elementary or less education. Contributions of ages between 35 and 49 to the educational differences in life expectancy were greater than those of ages other age groups. This was true for the educational differences between college or higher education and elementary or less education and true for the differences between middle or high school and elementary or less education. Meanwhile, older age groups aged 60-64 and over contributed significantly to the educational differences in life expectancy between middle or high school and college or higher education.

Figure 1 also presents age-specific contributions in Korean adult women. Among women, younger age groups between 25 and 39 showed greater contributions than other older age groups. This was true for educational differences between college or higher education and elementary or less education and true for between middle or high school and elementary or less education. Meanwhile, older age groups aged over 65 contributed significantly to the educational differentials in life expectancy.

Table 3 presents cause-specific contributions to the life expectancy gap by education in Korean men. In broad causes of deaths, the contributions by cancers were greater than those of cardiovascular diseases in men while in women the contributions by cardiovascular diseases surpassed the contributions by cancers. This pattern was true

Table 2 Numbers of subjects and deaths, and life expectancy at age $\mathbf{2 5}$ by education levels among Korean men and women

\begin{tabular}{|c|c|c|c|c|}
\hline Education & No. of subjects & No. of deaths & Life expectancy at age 25 & Life expectancy difference \\
\hline \multicolumn{5}{|l|}{ Men } \\
\hline Total & 15215523 & 129940 & 48.390 & \\
\hline Elementary or less & 1862582 & 63705 & 36.189 & 16.226 \\
\hline Middle or high school & 7653323 & 51562 & 48.503 & 3.912 \\
\hline College or higher & 5699618 & 14673 & 52.415 & Reference \\
\hline \multicolumn{5}{|l|}{ Women } \\
\hline Total & 16077137 & 106188 & 54.754 & \\
\hline Elementary or less & 4105545 & 87583 & 48.891 & 7.692 \\
\hline Middle or high school & 7927474 & 15823 & 55.453 & 1.130 \\
\hline College or higher & 4044118 & 2782 & 56.583 & Reference \\
\hline
\end{tabular}



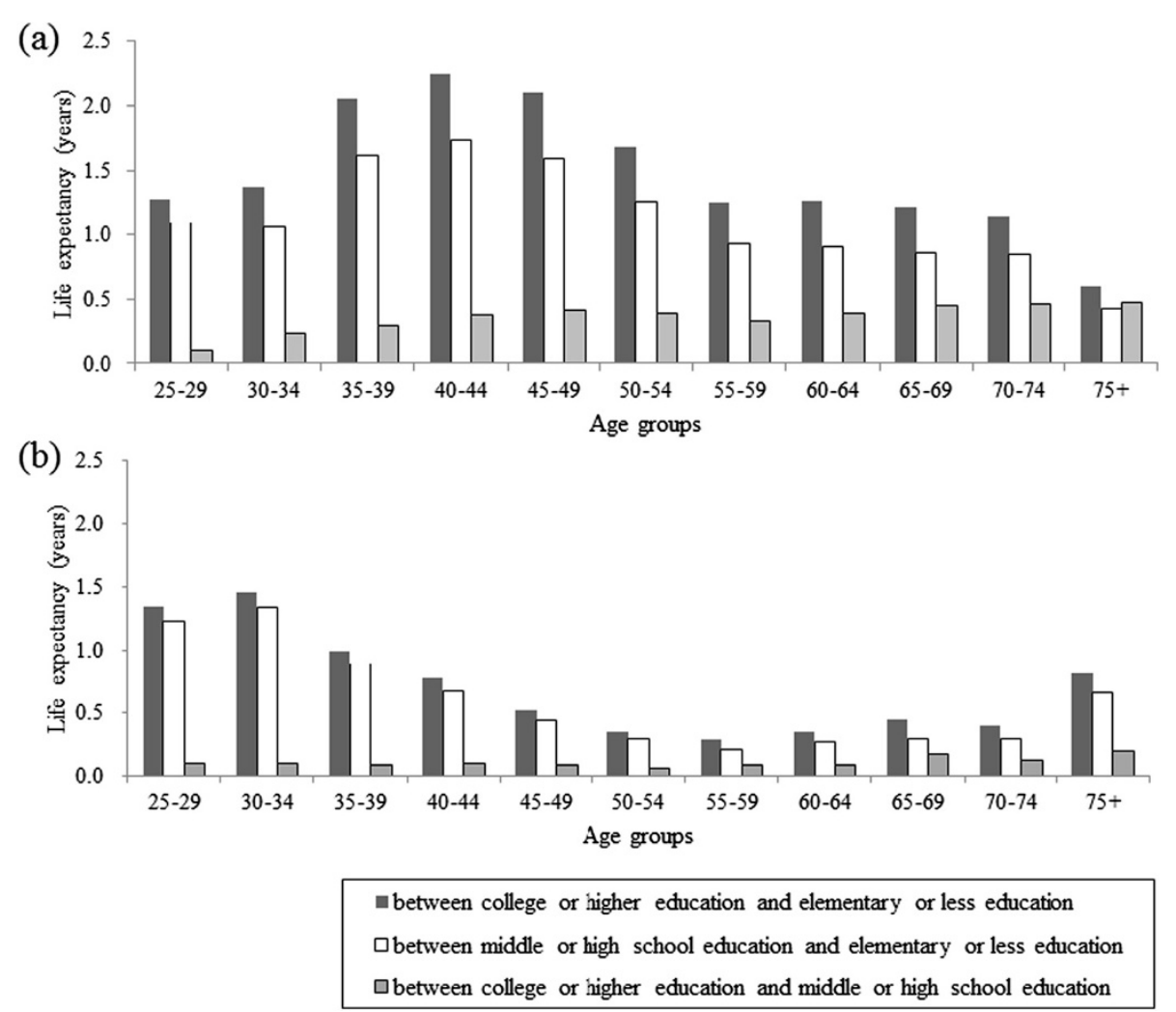

Figure 1 Age-specific contributions to the educational gaps in life expectancy at age 25 among Korean (a) men and (b) women.

for all the comparisons between educational levels considered. In both men and women, the contributions by external causes were significant, substantially accounting for total educational differences in life expectancy (about $28-29 \%$ in men and $20-24 \%$ in women).

Table 3 also shows contributions by specific causes. Liver disease, suicide, transport accident, cerebrovascular disease, and lung cancer played important roles in explaining educational differences in life expectancy in men. Especially, the most important contribution among specific causes was made by liver disease, explaining about $9-12 \%$ of total educational differences in life expectancy between college or higher education and elementary or less education and between middle or high school and elementary or less education. These large contributions were not found in women. In addition, suicide in men was the most important contributor to the educational differentials in life expectancy between middle or high school and college or higher education and the second most important contributors to other educational differences. In women, cerebrovascular disease, suicide, transport accident, liver disease, and diabetes mellitus were the main contributors to life expectancy differences by educational levels. Among those, contributions by cerebrovascular disease and suicide were most important. The leading cancers in Korea, lung, stomach, and liver cancers, showed relatively greater mortality rates in low education groups than high education group and thus positively contributed to the educational differences in life expectancy among both men and women. However, prostate cancer and colorectal cancer among men and breast cancer and colorectal cancer among women contributed negatively to the differences in life expectancy by some educational levels. Ill-defined causes were also in accounting for educational life expectancy differences in both men and women.

Figure 2 presents patterns of contributions by major causes of deaths to educational life expectancy differences by age groups. In men, suicide and liver disease contributed significantly to the educational differences in life expectancy in younger ages between 35 and 49, while major contributions by lung cancer and cerebrovascular disease were found among men aged 60 or over. Similar findings were observed among women. Suicide and liver disease showed important contributions in younger age groups such as ages 35-39 while in older age groups of women diabetes mellitus, cerebrovascular disease, and ischaemic heart disease contributed significantly 
Table 3 Cause-specific contributions (years and\%) to life expectancy gap by education among Korean men and women

\begin{tabular}{|c|c|c|c|c|c|c|}
\hline \multirow[t]{2}{*}{ Cause of death } & \multicolumn{3}{|c|}{ Men } & \multicolumn{3}{|c|}{ Women } \\
\hline & I vs. III & I vs. II & II vs. III & I vs. III & I vs. II & II vs. III \\
\hline All causes & $16.226(100.0)$ & $3.912(100.0)$ & $12.314(100.0)$ & $7.692(100.0)$ & $1.130(100.0)$ & $6.562(100.0)$ \\
\hline Infectious and parasitic diseases (A00-B99) & $0.790(4.87)$ & $0.144(3.69)$ & $0.655(5.32)$ & $0.233(3.03)$ & $0.033(2.88)$ & $0.198(3.02)$ \\
\hline Tuberculosis (A15-A19) & $0.504(3.10)$ & $0.097(2.49)$ & $0.423(3.44)$ & $0.126(1.63)$ & $0.023(2.02)$ & $0.100(1.52)$ \\
\hline Other infectious diseases & $0.286(1.76)$ & $0.047(1.20)$ & $0.232(1.88)$ & $0.108(1.40)$ & $0.010(0.86)$ & $0.098(1.50)$ \\
\hline All Cancers (C00-D48) & $2.799(17.25)$ & $0.857(21.91)$ & $1.945(15.80)$ & $1.041(13.54)$ & $0.113(10.04)$ & $0.921(14.03)$ \\
\hline Stomach cancer (C16) & $0.529(3.26)$ & $0.117(2.98)$ & $0.493(4.01)$ & $0.183(2.38)$ & $0.025(2.20)$ & $0.155(2.36)$ \\
\hline Colorectal cancer (C18-C21) & $0.017(0.10)$ & $0.001(0.02)$ & $-0.010(-0.08)$ & $0.062(0.81)$ & $-0.001(-0.11)$ & $0.064(0.98)$ \\
\hline Liver cancer (C22) & $0.669(4.12)$ & $0.188(4.81)$ & $0.441(3.58)$ & $0.179(2.33)$ & $0.025(2.17)$ & $0.155(2.36)$ \\
\hline Lung/bronchial cancer (C33-C34) & $0.928(5.72)$ & $0.334(8.54)$ & $0.677(5.50)$ & $0.179(2.33)$ & $0.052(4.61)$ & $0.123(1.87)$ \\
\hline Breast cancer (C50) & - & - & - & $0.058(0.75)$ & $-0.015(-1.32)$ & $0.072(1.10)$ \\
\hline Uterine cervix/unspecified uterine cancer (C53-C55) & - & - & - & $0.108(1.40)$ & $0.023(2.04)$ & $0.084(1.28)$ \\
\hline Prostate cancer (C61) & $-0.028(-0.17)$ & $-0.033(-0.83)$ & $-0.026(-0.21)$ & - & - & - \\
\hline Other cancers & $0.685(4.22)$ & $0.250(6.40)$ & $0.371(3.01)$ & $0.272(3.54)$ & $0.005(0.45)$ & $0.267(4.08)$ \\
\hline Endocrine, nutritional \& metabolic diseases (E00-E88) & $0.554(3.42)$ & $0.154(3.94)$ & $0.313(2.54)$ & $0.376(4.88)$ & $0.113(10.03)$ & $0.248(3.77)$ \\
\hline Diabetes mellitus (E10-E14) & $0.474(2.92)$ & $0.138(3.52)$ & $0.243(1.97)$ & $0.337(4.38)$ & $0.106(9.41)$ & $0.217(3.30)$ \\
\hline Other endocrine diseases & $0.080(0.49)$ & $0.017(0.42)$ & $0.056(0.45)$ & $0.039(0.50)$ & $0.007(0.62)$ & $0.028(0.43)$ \\
\hline Disease of the circulatory system (100-199) & $1.949(12.01)$ & $0.612(15.65)$ & $1.167(9.48)$ & $1.624(21.11)$ & $0.328(29.01)$ & $1.287(19.62)$ \\
\hline Hypertensive disease (110-113) & $0.068(0.42)$ & $0.039(1.00)$ & $0.044(0.36)$ & $0.109(1.41)$ & $0.040(3.52)$ & $0.066(1.01)$ \\
\hline Ischaemic heart disease (120-125) & $0.318(1.96)$ & $0.062(1.57)$ & $0.156(1.27)$ & $0.273(3.55)$ & $0.065(5.72)$ & $0.206(3.13)$ \\
\hline Cerebrovascular disease (160-169) & $1.117(6.88)$ & $0.416(10.63)$ & $0.661(5.37)$ & $0.801(10.41)$ & $0.168(14.84)$ & $0.640(9.75)$ \\
\hline Other cardiovascular diseases & $0.447(2.75)$ & $0.096(2.45)$ & $0.306(2.48)$ & $0.441(5.74)$ & $0.056(4.93)$ & $0.376(5.73)$ \\
\hline Diseases of the respiratory system (J00-J98) & $0.833(5.13)$ & $0.212(5.43)$ & $0.809(6.57)$ & $0.329(4.28)$ & $0.078(6.87)$ & $0.252(3.85)$ \\
\hline Pneumonia (J12-J18) & $0.191(1.18)$ & $0.030(0.76)$ & $0.172(1.40)$ & $0.095(1.23)$ & $0.015(1.36)$ & $0.079(1.20)$ \\
\hline Chronic lower respiratory disease (J40-J47) & $0.445(2.74)$ & $0.155(3.96)$ & $0.418(3.39)$ & $0.163(2.12)$ & $0.036(3.17)$ & $0.133(2.03)$ \\
\hline Other respiratory diseases & $0.196(1.21)$ & $0.028(0.71)$ & $0.219(1.78)$ & $0.071(0.92)$ & $0.027(2.35)$ & $0.041(0.62)$ \\
\hline Diseases of the digestive system (K00-K92) & $2.110(13.00)$ & $0.408(10.44)$ & $1.684(13.68)$ & $0.479(6.23)$ & $0.091(8.01)$ & $0.377(5.75)$ \\
\hline Liver diseases (K70-K76) & $1.891(11.65)$ & $0.361(9.22)$ & $1.505(12.22)$ & $0.349(4.54)$ & $0.067(5.91)$ & $0.274(4.18)$ \\
\hline Other digestive diseases & $0.219(1.35)$ & $0.048(1.22)$ & $0.179(1.46)$ & $0.130(1.69)$ & $0.024(2.10)$ & $0.103(1.57)$ \\
\hline All external causes (V01-Y89) & $4.665(28.75)$ & $1.099(28.09)$ & $3.509(28.50)$ & $1.574(20.46)$ & $0.271(24.01)$ & $1.296(19.75)$ \\
\hline Transport accidents (V01-V99) & $1.197(7.38)$ & $0.317(8.09)$ & $0.866(7.03)$ & $0.370(4.81)$ & $0.052(4.64)$ & $0.319(4.86)$ \\
\hline Suicide (X60-X84) & $1.750(10.79)$ & $0.444(11.36)$ & $1.297(10.53)$ & $0.666(8.66)$ & $0.143(12.68)$ & $0.519(7.90)$ \\
\hline Other external causes & $1.717(10.58)$ & $0.338(8.64)$ & $1.347(10.94)$ & $0.538(6.99)$ & $0.076(6.69)$ & $0.458(6.99)$ \\
\hline III-defined (R00-R99) & $1.149(7.08)$ & $0.304(7.77)$ & $1.115(9.06)$ & $0.854(11.10)$ & $0.046(4.09)$ & $0.866(13.20)$ \\
\hline Residual & $1.377(8.49)$ & $0.120(3.07)$ & $1.116(9.06)$ & $1.183(15.37)$ & $0.057(5.06)$ & $1.116(17.01)$ \\
\hline
\end{tabular}

Note: I = College or higher, $\mathrm{II}=$ Middle or high school, $\mathrm{III}=$ Elementary or less.

to the education life expectancy differences. Meanwhile, the magnitude of contribution by ischaemic heart disease was small or negative in older age men.

\section{Discussion}

Differences in life expectancy at age 25 between elementary or lower education (6 or less year schooling) and college or higher education (13 or more year schooling) in Korea were 16.23 years in men and 7.69 years in women.
In Finland, the differences in life expectancy at age 30 between low education with 9 or less year schooling and high education with 13 or more year schooling were 6.96 years in men and 3.88 years in women in 1998-99, whereas the same educational differences in life expectancy at age 30 in Russia were 13.08 years in men and 10.21 years in women in 1998 [25,26]. The differences in life expectancy at age 25 between primary or lower education and university education in Lithuania were 16.75 years in men 


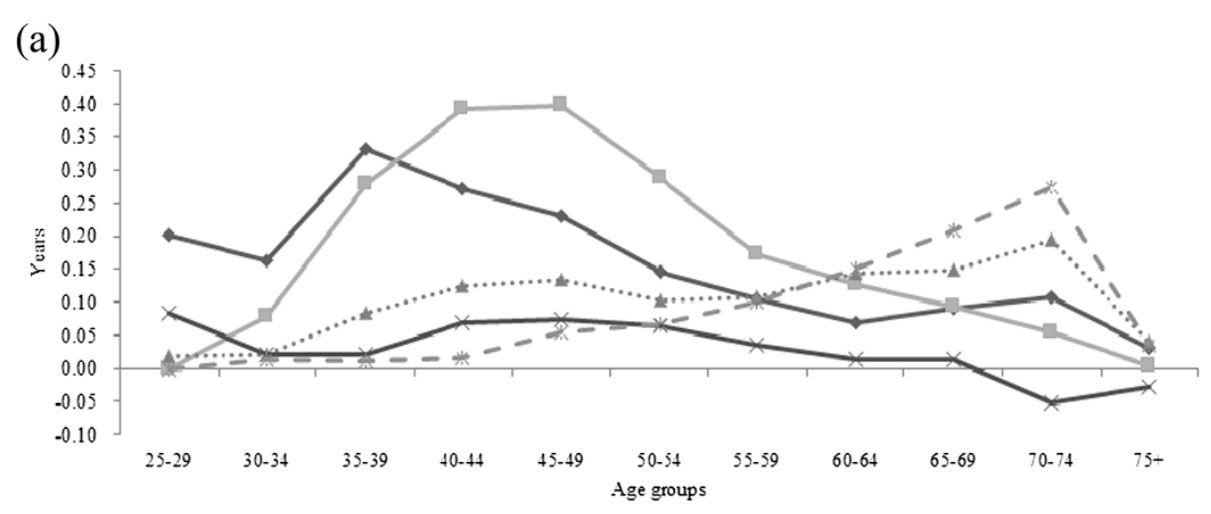

(b)

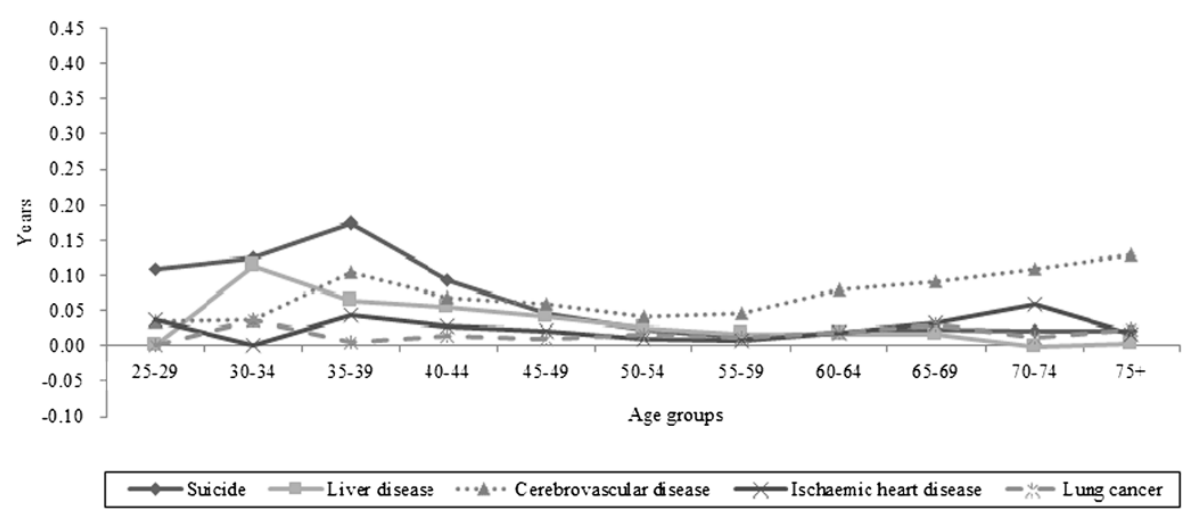

Figure 2 Age- and cause-specific contributions by major causes of deaths to educational differences in life expectancy at age 25 between college or higher education and elementary or less education among Korean (a) men and (b) women.

and 15.20 years in women in 2001 [27]. In Denmark, the educational differences in life expectancy at age 30 between primary or lower secondary education and tertiary education were 6.4 years in men and 4.7 years in women in 2011 [28]. Although it is hard to directly compare the magnitude of educational differences in life expectancy between countries due to the different educational categories and the study periods, results of this study suggest that the size of the educational differences in life expectancy seems to be relatively greater than that in northern European countries.

Younger age groups were more important contributors to the educational differentials in life expectancy between elementary or less education and other two higher educational groups, while older age groups were more important in explaining the difference between middle or high school education and college or higher education. This was generally true for both men and women in this study. This may mean that the dismal effects of poor socioeconomic environment would appear at younger ages among people with extreme social disadvantages (i.e., elementary or less education among young ages). In Korea where the enrollment rate in middle school increased from $42 \%$ in 1970 to over $90 \%$ in 1990
[20], only $0.4-13.0 \%$ of people aged $25-49$ had elementary or less educational attainment [21]. People with elementary or less education aged less than 35 years may signify the extreme social exclusion in Korea. These young and socially marginalized population in Korea might have experienced neo-liberal structural reforms resulting in increases in unemployment rates, enhancement of labor flexibility, and rise of income inequality as well as lack of generous social safety net during the periods of the economic crisis in 1998 and the credit card crisis in 2003. The main contributing causes of deaths at those age groups to the educational differences in life expectancy were suicide and liver disease in both genders.

Korea has recorded the highest suicide rates among the Organization of Economic Co-operation and Development (OECD) member countries starting 2003 with upsurges during the Korea's economic crisis in late 1990s and during the credit card crisis in 2003 [29,30]. Suicide is the most frequent cause of deaths in 20s' and 30s' men and women in Korea, although the elderly had the greater suicide rates than younger age groups [31]. Prior Korean studies showed that men and women aged 
35-44 had greater educational differentials in suicide mortality in both relative and absolute terms than older age groups [30,32]. Results of this study as well as other prior studies suggest that social changes into harsher labor market environment might have had a greater impact on socioeconomically marginalized educational groups with younger ages who did not have sufficient resources and skills to overcome socioeconomic difficulties in late 1990s and early 2000s.

The main risk factors for liver disease are viral hepatitis and alcohol abuse [33,34]. According to the 2007 National Health and Nutrition Examination Survey of Korea by the Korea Centers for Disease Control and Prevention, the prevalence of the hepatitis $B$ antigen positive among Koreans aged $19-49$ is $2.1-4.3 \%$ and the prevalence of hazardous alcohol use is 44.5-45.8\% [35]. Considering the relatively high rate of hepatitis $B$ infection and alcohol abuse in Korea, social inequalities in hepatitis B viral infection and hazardous alcohol use might well have contributed to the significant part of the socioeconomic inequalities in liver disease [36-38].

Cerebrovascular disease and lung cancer in older age groups were the important causes of death in terms of differentials in life expectancy at age 25 especially between middle or high school and college or higher education. Cerebrovascular disease may be related to adverse childhood living conditions, along with liver disease, liver cancer and stomach cancer $[39,40]$. Poor socioeconomic environments and their inequitable distribution during and after Japanese colonial occupation (1910-1945) and the Korean War (1950-1953) might have had effects on the socioeconomic inequalities in mortalities from these causes. The prevalence of cigarette smoking, the main risk factor of lung cancer, reached over $50 \%$ before early 2000 s with the highest rate being about $79 \%$ in 1980 among Korean men [41]. High smoking rates and high absolute differentials in smoking rates by educational level [42] might have contributed to the increase in mortality and mortality inequalities from lung cancer, especially in men. The percent contribution by cerebrovascular disease to the educational difference in life expectancy was greater among women than men while the percent contributions as well as absolute contributions (years) by lung cancer, stomach cancer, and liver cancer were greater in men than women. These results are similar to a previous study showing that, in women, the contribution of cerebrovascular disease was greater than that of cancer in southern and eastern European countries [1].

The biggest difference of the results in this study from findings in northern or western European countries is the size of the contribution by ischaemic heart disease to socioeconomic inequalities in mortality as indicated in prior Korean studies [32,43]. This study revealed that the contribution of ischemic heart disease was relatively small in Korea, accounting for $1-2 \%$ and $3-6 \%$ of total educational inequalities in life expectancy in men and women, respectively. Meanwhile, ischaemic heart disease was the most important contributor to total mortality inequalities in northern and western Europe [1,4]. However, mortality rates and absolute socioeconomic inequality in ischaemic heart disease are increasing rapidly in Korea [43]. Considering the secular trend of the westernized diet as risk factors for ischaemic heart disease in Korea [44], thorough monitoring on changes in socioeconomic inequalities of ischaemic heart disease is needed.

Our study has strengths and limitations. We presented age- and cause-specific contributions to the socioeconomic inequalities in life expectancy at age 25 using Arriaga's decomposition method, while most previous studies showed only age-specific contributions and/or cause-specific contributions. Detailed quantification of age- and causespecific contributions to socioeconomic inequalities in life expectancy allowed us to present varying age-specific contributions by each cause of deaths and to develop priority age groups and causes of deaths for each cause and age group. However, we used unlinked data with death certificate and census data which may produce a numerator-denominator bias [45]. A prior Korean study examined this issue [18]. When the educational level was categorized into three categories (elementary school or less, middle or high school graduate, college or higher), the percentage agreement between death certificate data and health survey data was $89.4 \%$ and the kappa value was 0.75 [18], which means the reliability level was substantial [46]. Thus, we believe that the numerator-denominator bias would be minimal.

\section{Conclusions}

Educational differences in life expectancy were substantial in Korea. Liver disease and suicide were important contributors to the differences among younger age groups while cerebrovascular disease and lung cancer were important among older age groups. The age specific contributions for different causes of death to life expectancy inequalities by educational attainment varied with educational comparisons. Different age-specific distributions in educational levels due to remarkable improvement in education during the past decades may explain the findings as each educational attainment as SEP can have distinct meanings in the context and history in the Korean society. Exploring age- and cause-specific contributions to socioeconomic inequalities in life expectancy could allow us to better understand the nature of socioeconomic mortality inequalities and to specifically suggest priority areas for policy and intervention.

Competing interests

The authors declare that they have no competing interests. 


\section{Authors' contributions}

KJC participated in study design and drafted the manuscript. YHK conceived the original idea for the study and gave critical comments on the draft manuscript. HJC participated in study design and critical revision of the manuscript. SCY supervised study design, performed the statistical analysis and gave critical comments on the draft manuscript. All authors read and approved the final manuscript.

\section{Author details}

'Department of Preventive Medicine, Ewha Womans University School of Medicine, Seoul, Korea. ${ }^{2}$ Department of Health Policy and Management \& Institute of Health Policy and Management, Seoul National University College of Medicine, Seoul, Korea. ${ }^{3}$ Department of Family Medicine, Asan Medical Center, University of Ulsan College of Medicine, Seoul, Korea. ${ }^{4}$ Department of Clinical Epidemiology and Biostatistics, Asan Medical Center, University of Ulsan College of Medicine, 388-1 Pungnap2-dong, Songpa-gu, Seoul 138-736, Korea.

\section{Received: 21 November 2013 Accepted: 27 May 2014}

Published: 5 June 2014

\section{References}

1. Mackenbach JP, Stirbu I, Roskam AJ, Schaap MM, Menvielle G, Leinsalu M, Kunst AE: Socioeconomic inequalities in health in 22 European countries. N Engl J Med 2008, 358:2468-2481.

2. Rosvall M, Chaix B, Lynch J, Lindstrom M, Merlo J: Contribution of main causes of death to social inequalities in mortality in the whole population of Scania. Sweden BMC Public Health 2006, 6:79.

3. Kunst AE, Groenhof F, Mackenbach JP: Occupational class and cause specific mortality in middle aged men in 11 European countries: comparison of population based studies. BMJ 1998, 316:1636-1642.

4. Huisman M, Kunst AE, Bopp M, Borgan JK, Borrell C, Costa G, Deboosere P, Gadeyne S, Glickman M, Marinacci C, Minder C, Regidor E, Valkonen T, Mackenbach JP: Educational inequalities in cause-specific mortality in middle-aged and older men and women in eight western European populations. Lancet 2005, 365:493-500.

5. Jung-Choi K, Khang YH, Cho HJ: Socioeconomic differentials in cause-specific mortality among 1.4 million South Korean public servants and their dependents. J Epidemiol Community Health 2011, 65:632-638.

6. Lin CC, Johnson NJ: Decomposition of life expectancy and expected life-years lost by disease. Statist Med 2006, 25:1922-1936.

7. Singh GK, Siahpush M: Widening socioeconomic inequalities in US life expectancy, 1980-2000. Int J Epidemiol 2006, 35:969-979.

8. Salomon JA, Wang H, Freeman MK, Vos T, Flaxman AD, Lopez AD, Murray CJL: Healthy life expectancy for 187 countries, 1990-2010: a systematic analysis for the Global Burden Disease Study 2010. Lancet 2012, 380:2144-2162.

9. Maki N, Martikainen P, Eikemo T, Menvielle G, Lundberg O, Ostergren O, Jasilionis D, Mackenbach JP: Educational differences in disability-free life expectancy: a comparative study of long-standing activity limitation in eight European countries. Soc Sci Med 2013, 94:1-8.

10. Bronnum-Hansen $\mathrm{H}$, Baadsgaard $\mathrm{M}$ : Widening social inequality in life expectancy in Denmark. A register-based study on social composition and mortality trends for the Danish population. BMC Public Health 2012, 12:994.

11. Meara ER, Richards S, Cutler DM: The gap gets bigger: changes in mortality and life expectancy, by education, 1981-2000. Health Aff 2008, 27(2):350-360.

12. Zhao $Y$, Dempsey $\mathrm{K}$ : Causes of inequality in life expectancy between Indigenous and non-indigenous people in the Norther Territory, 1981-2000: a decomposition analysis. Med J Aust 2006, 184:491-494.

13. Khang YH, Yang S, Cho HJ, Jung-Choi K, Yun SC: Decomposition of socio-economic differences in life expectancy at birth by age and cause of death among 4 million South Korean public servants and their dependents. Int J Epidemiol 2010, 39:1656-1666.

14. Martikainen $P$ : Change in male and female life expectancy by social class: decomposition by age and cause of death in Finland 1971-95. J Epidemiol Community Health 2001, 55:494-499.

15. Kwon TH, Kim TH: Life table in Korea, 1970-1985. Seoul: Seoul National University Press; 1990.
16. Chung EK, Shin HY, Shin JH, Nam HS, Ryu SY, Im JS, Rhee JA: Accuracy of the registered cause of death in a county and its related factors. Korean J Prev Med 2002, 35:153-159.

17. Lee DH, Shin HR, Ahn DH, Chun BY, Kam S, Ahn YO: Accuracy of cancer death certificates in Korea: a comparison between diagnosis in the central cancer registry and certified underlying causes of death. J Korean Cancer Assoc 2000, 32:210-219.

18. Kim HR, Khang YH: Reliability of education and occupational class: a comparison of health survey and death certificate data. J Prev Med Pub Health 2005, 38:443-448.

19. OECD: Classifying Educational Programmes. Paris: OECD Publications; 1999.

20. Lee CJ, Kim S, Adams D: Sixty Years of Korean Education. Seoul: Seoul National University Press; 2009.

21. Korea S: 2005 population and housing census report: based on complete enumeration. Volume 1. Population. Daejeon: Statistics Korea; 2006

22. Arriaga EE: Measuring and explaining the change in life expectancies. Demography 1984, 21:83-96.

23. European Health Expectancy Monitoring Unit: WP7: Decomposition tools. Technical report on decomposition. Montpellier: EHEMU; 2010.

24. Korea S: The Causes of Death Statistics in 2005. Daejeon: Statistics Korea; 2006.

25. Shkolnikov VM, Andreev EM, Jasilionis D, Leinsalu M, Antonova Ol, McKee M: The changing relation between education and life expectancy in central and eastern Europe in the 1990s. J Epidemiol Community Health 2006, 60:875-881.

26. Shkolnikov V, Kravdal $\varnothing$, Valkonen T, Deev AD: Educational differentials in male mortality in Russia and northern Europe. Demogr Res 2004, 10:1-26.

27. Kalediene R, Starkuviene S, Petrauskiene J: Inequalities in life expectancy by education and socioeconomic transition in Lithuania. Medicina 2008, 44:713-722.

28. Bronnum-Hansen $\mathrm{H}$, Baadsgaard M: Increasing social inequality in life expectancy in Denmark. Eur J Public Health 2007, 17:585-586.

29. OECD: OECD health data 2013. [http://stats.oecd.org/index.aspx? DataSetCode=HEALTH_STAT]

30. Lee WY, Khang YH, Noh M, Ryu Jl, Son M, Hong YP: Trends in educational differentials in suicide mortality between 1993-2006 in Korea. Yonsei Med J 2009, 50:482-492.

31. Kim MH, Jung-Choi K, Jun HJ, Kawachi I: Socioeconomic inequalities in suicidal ideation, parasuicides, and completed suicides in South Korea. Soc Sci Med 2010, 70:1254-1261.

32. Khang YH, Lynch JW, Kaplan GA: Health inequalities in Korea: age- and sex-specific educational differences in the 10 leading causes of death. Int J Epidemiol 2004, 33:299-308.

33. Starr SP, Raines D: Cirrhosis: diagnosis, management, and prevention. Am Fam Physician 2011, 84:1353-1359.

34. Blachier M, Leleu H, Peck-Radosavljevic M, Valla DC, Roudot-Thoraval F: The burden of liver disease in Europe: a review of available epidemiological data. J Hepatol 2013, 58:593-608.

35. Korea Centers for Disease Control: Korea Health Statistics 2007: Korea National Health and Nutrition Examination Survey. Seoul: Ministry of Health \& Welfare; 2008.

36. Pereira LM, Martelli CM, Merchan-Hamann E, Montarroyos UR, Braga MC, de Lima ML, Cardoso MR, Turchi MD, Costa MA, de Alencar LC, Moreira RC, Figueiredo GM, Ximenes RA: Population-based multicentric survey of hepatitis $B$ infection and risk factor differences among three regions in Brazil. Am J Trop Med Hyg 2009, 81:240-247.

37. Park SH, Kim CH, Kim DJ, Suk KT, Park HY, Lee JG, Shin KJ, Park JH, Kim TO, Yang SY, Moon YS, Lee HY: Secular trends in prevalence of alcohol use disorder and its correlates in Korean adults: results from Korea National Health and Nutrition Examination Survey 2005 and 2009. Subst Abus 2012, 33:327-335.

38. Meffre C, Le Strat Y, Delarocque-Astagneau E, Dubois F, Antona D, Lemasson JM, Warszawski J, Steinmetz J, Coste D, Meyer JF, Leiser S, Giordanella JP, Gueguen R, Desenclos JC: Prevalence of hepatitis B and hepatitis $C$ virus infections in France in 2004: social factors are important predictors after adjusting for known risk factors. J Med Virol 2010, 82:546-555.

39. Smith GD, Hart C, Blane D, Hole D: Adverse socioeconomic conditions in childhood and cause specific adult mortality: prospective observational study. BMJ 1998, 316:1631-1635.

40. Galobardes B, Lynch JW, Davey SG: Childhood socioeconomic circumstances and cause-specific mortality in adulthood: systematic review and interpretation. Epidemiol Rev 2004, 26:7-21. 
41. Lee HH: National Tobacco Control Programmes. Health Welf Policy Forum 2007, 7:6-21.

42. Khang YH, Yun SC, Cho HJ, Jung-Choi K: The impact of governmental antismoking policy on socioeconomic disparities in cigarette smoking in South Korea. Nicotine Tob Res 2009, 11:262-269.

43. Jung-Choi K, Khang YH, Cho HJ: Changes in contribution of causes of death to socioeconomic mortality inequalities in Korean adults. J Prev Med Public Health 2011, 44:249-259.

44. Korea Centers for Disease Control: Korea Health Statistics 2011: Korea National Health and Nutrition Examination Survey. Seoul: Ministry of Health \& Welfare; 2012

45. Macintyre S: The Black Report and beyond: what are the issues? Soc Sci Med 1997, 44:723-745.

46. Landis JR, Koch GG: The measurement of observer agreement for categorical data. Biometrics 1977, 33:159-174.

doi:10.1186/1471-2458-14-560

Cite this article as: Jung-Choi et al: Decomposition of educational differences in life expectancy by age and causes of death among South Korean adults. BMC Public Health 2014 14:560.

\section{Submit your next manuscript to BioMed Central and take full advantage of:}

- Convenient online submission

- Thorough peer review

- No space constraints or color figure charges

- Immediate publication on acceptance

- Inclusion in PubMed, CAS, Scopus and Google Scholar

- Research which is freely available for redistribution 